JGG 2021;69:155-163

doi: $10.36150 / 2499-6564-N 343$

\title{
Factors associated with history of fall among older people in Southern West Bank
}

\author{
Manal M. Badrasawi ${ }^{1}$, Nihal O. Natour ${ }^{2}$, Alaa Jaradat ${ }^{3}$ \\ ${ }^{1}$ Department of Nutrition and Food technology, Faculty of Agriculture and Veterinary Medicine, An- \\ Najah National University, Tulkarm, Palestine; ${ }^{2}$ Department of Public Health, School of Medicine, \\ An-Najah National University, Nablus, West Bank, Palestine; ${ }^{3}$ Healthy and therapeutic nutrition, \\ College Of Medicine \& Health Science; Palestine Polytechnic University, Hebrone, West Bank, \\ Palestine
}

Objective. Older men and women have higher risk of fall due to various factors. Among Palestinian older adults fall history yet to be studied in terms of prevalence and correlates. The primary objective of this study is to determine the prevalence of fall and the differences between fallers and non-fallers among a group of Palestinian older living in rural areas in Southern West Bank region of Hebron.

Methods. The study included 142 participants from two villages: Se'ar and Bani Na'em, Hebron governance. Demographic variables and fall history was collected. Anthropometric measurement were used to assess nutritional status; physical function was assessed. Geriatric scale for depression and Montreal cognitive assessment test.

Results. $51.7 \%$ of study participants were females, the mean age $69.5 \pm 5.7$ years old. Positive fall history was present among $11.7 \%$ mostly females. Significant relationship was found between fall and larger waist and hip circumference, cognitive impairment, higher level of dependency and slower performance in time up and go (TUG) $\mathrm{p}<0.05$.

Received: January 13, 2021

Accepted: March 15, 2021

\section{Correspondence}

Nihal Natour

Department of Public Health, School of Medicine, An-Najah National University, Nablus, West Bank, PO BOX 7, Palestine. E-mail: n.natour@najah.edu

How to cite this article: Badrasawi MM, Natour NO, Jaradat A, et al. Factors associated with history of fall among older people in Southern West Bank. Journal of Gerontology and Geriatrics 2021;69:155-163. https://doi.org/10.36150/2499-6564-N343

(C) Copyright by Società Italiana

di Gerontologia e Geriatria (SIGG)

\section{(c) (1) $(9)$}

\section{OPEN ACCESS}

This is an open access article distributed in accordance with the CC-BY-NC-ND (Creative Commons Attribution-NonCommercial-NoDerivatives 4.0 International) license. The article can be used by giving appropriate credit and mentioning the license, but only for non-commercial purposes and only in the original version. For further information: https://creativecommons.org/licenses/by-nc-nd/4.0/deed.en
Conclusions. Fall history has considerable prevalence among the study sample and it is correlated with nutritional status, cognitive and physical function.

Key words: fall history, cognitive impairment, muscle function, older adults

\section{INTRODUCTION}

There is Global increase in aging people (population $\geq 65$ ) worldwide by $3 \%$ from 1950 to $2009{ }^{1}$. In 2015, aging population was $8.5 \%$ of total population ${ }^{2}$. According to Palestinian Bureau of statistics life expectancy for Palestinian males is $72.1 \mathrm{y}$ and for females $75.2 \mathrm{y}^{3}$. Due to high fertility rate and high proportion of younger population, older Palestinian population $\geq 65$ was only $2.9 \%$ of total population in $200{ }^{4}$. Aging population face higher risk of falls with consequent severe injury disability, decreased functional capacity and increased health cost ${ }^{5}$. It is estimated that $6 \%$ of falls in older will lead to fracture ${ }^{6}$. Rate of fall in some population may be as high as $30 \%^{7}$. History of falls in elder Palestinians has not been studied before.

Risk factors for falls include impairment in sensory, muscle function and cognition, specific diseases and medication use ${ }^{8}$. Factors like gait, 
balance and muscle strength all have been associated with risk of fall ${ }^{9}$. Moderate to severe cognitive problems are associated with double risk falling ${ }^{10}$. In addition, depressive symptoms increase the risk of fall in older people ${ }^{11}$.Combined physical and cognitive decline can lead to higher risk of fall ${ }^{12}$.

The double burden of obesity and sarcopenia increase the risk of fall in elder population. Sarcopenia is gradual decrease in muscle strength and function. Declined muscle mass is replaced by fat tissue with consequent increase in obesity ${ }^{13}$. Sarcopenic individuals have 60\% increases in the odds of falling in meta-analysis of studies on older $\geq 65^{14}$. On the other hand, obese people expressed more fear of falling and higher risk of falling, in addition, to significant association between waist circumference and fall ${ }^{15}$.

Various measures of physical functions have been used to track the wellbeing of older population including basic and instrumental activities of daily living (ADLs and IADLs), physical performance measures gait speed, timed up and go (TUG), chair stand test and other measures, and muscle function tests such as hand grip that were scarcely studied in relation to fall risk 16,17 . More studies using physical functions in relation to fall risk are needed. For example, grip strength is used as a biomarker to reflect aging and body function as it related directly to muscle strength for both sick and healthy older people ${ }^{18}$. Another example, ADL which is used to assess dependence on other caring party and independent functioning in ones' environment ${ }^{19}$.

Mild cognitive impairment $(\mathrm{MCl})$ which is considered a transition stage between normal aging and dementia and is associated with two fold increase in falls risk ${ }^{20}$. Some studies associate falls differentially according to cognitive decline severity, but it seems that non-Alzheimer disease dementia is linked more strongly to falls indicating that the type of cognitive impairment defines the relationship to fall risk ${ }^{21}$. This relationship has not been studied before among Palestinian population.

This study aims to study the association between nutritional status, body composition with fall risk and the relationship between fall risk with cognitive and physical function among randomly selected older adults in southern area of West Bank.

\section{METHODS}

\section{StUdY DESIGN}

This cross-sectional study was carried out in two villages: Se'ar and Bani Na'em, Hebron governance, in the south of the West Bank, Palestine. It was conducted between February and April 2019. The random sampling procedure was used to recruit 130 participants using Cochran's (1963) equation for prevalence studies. The prevalence of fall history was taken from similar previous study which found fall history prevalence $(35.5 \%)^{22}$. The sample size was increased to 150 participants considering the possible drop out. However, 5 were excluded due to missing data, and finally 145 participants (72 men and 78 women) were included in the final analysis with a $96 \%$ response rate.

The inclusion criteria were individuals aged 60 or above, living in the selected areas and agreed to take part in the study. Whereas the exclusion criteria were the presence of acute illness on the days of data collection, current fractures of extremities, having medical conditions that may limit their ability to perform the tests (such as patients with cachexia, sever edema or ascites) and dementia. The researcher verbally informed all the participants about the objectives of the study and gave them written informed consents. Only the participants who signed the consent form included in the study.

\section{Collected datA AND StUdy INSTRUMentS}

The research team used a pretested, structured questionnaire to collect the data from the participants face to face. The collected data included participants' sociodemographic (i.e. gender, marital status, educational level, monthly income, working status, living status, medical history included the self-reported presence of 15 chronic diseases in addition to previous surgery and fall history in the last year, nutritional status assessment, functional status assessment, cognitive function, and mental health.

The nutritional status assessment was done using anthropometric measurements. Anthropometric indices including (weight, height, mid-upper arm circumference (MUAC), waist circumference (WC), hip circumference $(\mathrm{HC})$ and calf circumference $(\mathrm{CC})$ were used to examine the nutritional status of the subjects according to the standard anthropometric procedures described by Lee \& Nieman (2007). The height measure was performed using a measuring tape. Body weight was measured using a calibrated electronic sensor scale. Body mass index was calculated as (body in kilogram divided by height squared in meter $\left(\mathrm{kg} / \mathrm{m}^{2}\right)$.

Waist and hip circumferences were measured using a flexible, non-extensible measuring tape. Mid upper arm circumference (MUAC) was measured on the right hand and used to identify subjects with muscle wasting due to malnutrition according to the following cut-off points: $<23 \mathrm{~cm}$ for men, and $<22 \mathrm{~cm}$ for women. Calf circumference was measured using a measuring tape; and muscle wasting was defined using the following cut-off points: $<30.1 \mathrm{~cm}$ for men, and $<27.3 \mathrm{~cm}$ for women. Being faller was defined as having previous history of falls and non-faller as lack of history of fall. 
Physical function assessment was performed by functional status assessment using ADL and IADL. Physical fitness was done using senior fitness tests. The senior fitness test is one of the tools being used in standard fitness assessment for older adults. It is a comprehensive assessment instrument that provides continuous scale measures. In this study the following tests were chosen for physical fitness assessment of the participants: handgrip for upper body strength, which is a valid predictive measure for age related disorders ${ }^{23}$; 30 seconds chair stand test as a reliable and valid indicator for lower body strength ${ }^{24}$; back scratch test for upper body flexibility; set and reach for lower body flexibilit y ${ }^{25}$; 8-ft time up and go as a valid test for balance ${ }^{25}$; 2 -minute step test to assess cardiovascular fitness and endurance ${ }^{25}$; and gait speed for pace assessment ${ }^{25}$. The activity of daily living was assessed using the Katz index scale; and instrumental activity of daily living was assessed using the Lawton scale.

To assess depressive symptoms, a 15-item Geriatric Scale for Depression (GDS-15) was used. This scale was validated with $84 \%$ sensitivity and $95 \%$ specificity. The Arabic version of Montreal Cognitive Assessment - Basic (MoCA-B) developed to facilitate the detection of mild cognitive impairment in illiterate and lower educated subjects was used. The MoCA-B assesses similar cognitive domains as the original MoCA including executive functions, language, orientation, calculations, conceptual thinking, memory, visual-perception, attention, and concentration. It is a 30-point score scale where a score below 24 suggests mild cognitive impairment.

\section{Statistical ANALYsis}

The Statistical Package for the Social Sciences SPSS $\mathrm{TM}$, version 21 was used to analyze the collected data, $5 \%$ alpha level and $80 \%$ power were considered in all of the statistical tests. Descriptive analysis including the means and the standard deviations were used to analyze the continuous data. The categorical data were described by percentages. The Independent Samples t-test was used to determine the significant differences in the mean scores of nutritional status, cognitive function and physical function variables between males and females. The prevalence of fall history was presented in percentages. The association between history of fall and independent categorical variables (i.e. gender, marital status, educational level and medical history) was carried out using the Chi-square test. The independent samples t-test was conducted to examine the relationship between faller participants with non-fallers participants in the following variables: anthropometric measurement, cognitive function, depressive symptoms and physical function tests.

\section{RESULTS}

Subjects were selected from two village in Hebron district Sa'er and Bani Na'em. A total of 150 participants were invited to join the study and verbally consent to join the study. One hundred forty five participants were included in the final analysis, 5 participants were excluded due to missing of primary data. The mean age of the participants was $69.5 \pm 5.7$ years, ranged from 60-90 years old.

Table I shows the subjects' distribution presented in number and percentage, the women composed the majority of the study sample $78 \%$. The majority of the subjects were married $70.3 \%$ primary educated $64 \%$, doesn't work 84\% and non-smoker 66\%, and 96.6\% living with family. Around half of the participants 57.7\% reported their ability to read, $51.2 \%$ to write and $51 \%$ able to calculate.

The results of the medical history revealed considerable prevalence of cardiovascular diseases among the participants; hypertension was reported among 46.5\% of the participates, followed by diabetes mellitus was reported among $28.7 \%$ of the participants as shown in Figure 1.

Table II, showed the nutritional status, physical and cognitive profiles of the participants according to gender, the results revealed women have higher BMI score as compared to men, while the women cognitive function test MOCA score was significantly lower than men. In regard to physical function the women showed lower level of fitness in the following tests; 2 min step test, TUG, hand grip and back scratch test as compared to men, $p<0.05$. Generally, 32.3\% of the participants had normal weight, 34.7\% were overweight, whilst 37.3\% were obese. According to Mini nutrition assessment MNA; $2 \%$ of the participant were malnourished, $17.3 \%$ are at risk of malnutrition, whilst the majority $80 \%$ are well-nourished.

The prevalence of history of fall was $11.7 \%$ with significant higher prevalence among women $20 \%$ as compared to men $2.9 \%, p<0.05$.

The results of the nutritional status profile based on history of fall are presented in Table III. The means of the $\mathrm{BMI}$ and hip circumference were significantly higher in fallers as compared to non-fallers $(p<0.05)$. the MUAC and CC was lower among fallers as compared to nonfaller but these differences were not significant.

As shown in Table IV, among the physical function tests 2 min step test, time up and go and rapid gate had significant relationships $(p<0.05)$ between fallers and non-fallers. Participants with fall history had a lower physical function performance as compared to nonfallers.. In regards to cognitive function, MOCA scores 
Table I. Subjects characteristics presented in numbers and percentages.

\begin{tabular}{|c|c|c|c|}
\hline $\begin{array}{l}\text { Demographic } \\
\text { characteristics }\end{array}$ & Value & $\begin{array}{c}\text { Total } \\
\text { number(n) }\end{array}$ & \\
\hline \multirow[t]{2}{*}{ Gender } & Male & 70 & 48.3 \\
\hline & Female & 75 & 51.7 \\
\hline \multicolumn{4}{|l|}{ Age } \\
\hline & $<70$ years & 95 & $\begin{array}{l}65.5 \\
34.5\end{array}$ \\
\hline & $>70$ years & 50 & \\
\hline \multicolumn{4}{|l|}{ Marital status } \\
\hline & Single & 22 & $\begin{array}{l}15.2 \\
70.3 \\
14.5 \\
\end{array}$ \\
\hline & Married & 102 & \\
\hline & Widow & 21 & \\
\hline \multicolumn{4}{|c|}{ Level of education } \\
\hline & Primary & 65 & $\begin{array}{c}44.8 \\
17.2 \\
2.1 \\
6.2 \\
29.7\end{array}$ \\
\hline & Secondary & 25 & \\
\hline & Diploma & 3 & \\
\hline & University & 9 & \\
\hline & Others & 43 & \\
\hline \multicolumn{4}{|l|}{ Living status } \\
\hline & Live with family & 140 & $\begin{array}{c}96.6 \\
3.4\end{array}$ \\
\hline & Live alone & 5 & \\
\hline \multicolumn{4}{|l|}{ Work status } \\
\hline & Working full time & 30 & $\begin{array}{c}20.7 \\
19.3 \\
55.2 \\
4.8 \\
\end{array}$ \\
\hline & Working part time & 28 & \\
\hline & Not working & 80 & \\
\hline & Retired & 7 & \\
\hline \multicolumn{4}{|l|}{ Income } \\
\hline & $500-1500$ & 55 & $\begin{array}{l}35.9 \\
51.6 \\
10.5\end{array}$ \\
\hline & $1501-3000$ & 79 & \\
\hline & $3001-5000$ & 16 & \\
\hline
\end{tabular}

were significantly higher in normal participants as compared to participants with fall history, but the difference didn't reached a significant level after the analysis done for males and females separately.

\section{DISCUSSION}

This study is a sample of Palestinian older from rural Hebron region who were mostly less than $70 \mathrm{y}$ and had low educational level. Fall history prevalence was 11.7\% in total population and is more common in females than males. This rate is lower than what was found in different population where fall history prevalence was higher than 35\% in developed countries such as UK and US ${ }^{26}$. In a study among Egyptian elder in Suez, 205 out of 340 reported falling at least once which is higher percent than this reported in our study ${ }^{27}$. The lower rate of fall in our study could be related to the fact that $65.5 \%$ of our study participants are less than $70 \mathrm{y}$, many of them are independent and still working, in addition to family social support they receive as most still live with their families.

Our results were similar to other reports with regards to preference prevalence of fall history in women relative to men ${ }^{28}$. Our results show that women in fact have lower cognitive performance as assessed by MoAC. In addition, physical performance tests such as 2 minute step test, TUG, hand grip, and back scratch test all were lower in females than males. In study among Brazilian participants, fall fear was more common among females and was associated with multiple use of medications, hearing impairment, poor gait speed and depression ${ }^{29}$. In more than one study, being female was associated with higher risk of falling or fear of fall which is serious health condition that prevent normal life activities ${ }^{30}$. Definitely having higher risk of falling among women along with the effect of menopause on bone mineral density could lead to higher rate of fracture and injury related mortality. Higher rate of fall among women could be related to the fact women live longer than men ${ }^{31}$.

In this study, most of older participants were still living with their families, a form of social protection which could have beneficial effect with regards to fall risk. In a study among Japanese older adults, social support significantly improved fall self-efficacy ${ }^{32}$. In another study by Trevisan et al., poor social support or social connection was twice more frequent among the older patients with severe or multiple falls ${ }^{33}$. Social resources that make the person feel loved, cared for, valued and part of network of communication is reduced in older people relative to young one and this affect their level of wellbeing and life quality, in Palestine and as was clear from this study older people tend to live with their extended families. However more studies are needed to understand the dynamic of the forms of social support provided by extended Palestinian families.

Indicators of obesity both central and hip were associated positively with fall history. In women, both hip and 
Table II. Participants nutritional status, cognitive and physical function profile according to gender.

\begin{tabular}{|l|l|c|c|c|}
\hline \multicolumn{2}{|c|}{} & $\begin{array}{c}\text { Male } \\
(\mathbf{n}=\mathbf{7 0})\end{array}$ & $\begin{array}{c}\text { Female } \\
(\mathbf{n}=\mathbf{7 5})\end{array}$ & P-value \\
\hline \multirow{4}{*}{ Nutritional status } & BMI & $27.5 \pm 4.4$ & $30.6 \pm 7.52$ & 0.004 \\
\cline { 2 - 5 } & MUAC & $34.5 \pm 3.4$ & $34.8 \pm 3.4$ & 0.123 \\
\cline { 2 - 5 } & W : Hip ratio & $1.1 \pm 1.03$ & $0.98 \pm 0.1$ & 0.234 \\
\cline { 2 - 5 } & Calf circumference & $33.1 \pm 5.3$ & $33.6 \pm 6.7$ & 0.324 \\
\cline { 2 - 5 } & No of meals/day & $4.2 \pm 1.04$ & $3.8 \pm 1.24$ & 0.073 \\
\cline { 2 - 5 } & MNA & & & \\
\hline Cognitive function & MOCA & $17.7 \pm 3.5$ & $14.5 \pm 2.6$ & $0.001^{*}$ \\
\hline Depression symptoms & GDS & $5 \pm 3.14$ & $5 \pm 2.57$ & 0.865 \\
\hline Functional status & ADL & $2.1 \pm 2.69$ & $1.8 \pm 2.51$ & 0.521 \\
\cline { 2 - 5 } & IADL & $5.4+1.37$ & $5.5+2.09$ & 0.774 \\
\hline Physical fitness & 2 min step test & $126.4+38.7$ & $98.1+50.6$ & $0.001^{*}$ \\
\cline { 2 - 5 } & TUG & $15.2+5.9$ & $20+18.8$ & $0.044^{*}$ \\
\cline { 2 - 5 } & Hand grip & $24.7+10.7$ & $18.6+7.02$ & $0.001^{*}$ \\
\cline { 2 - 5 } & Back scratch test & $26.6+17.5$ & $33.5+19.1$ & $0.034^{*}$ \\
\cline { 2 - 5 } & Set and reach & $3.3+3.9$ & $3.7+4.9$ & 0.549 \\
\cline { 2 - 5 } & Chair stand test & $17.5+11.6$ & $19.6+15.06$ & 0.365 \\
\cline { 2 - 5 } & Gate speed & $7.06+5.13$ & $8.76+6.9$ & 0.097 \\
\cline { 2 - 5 } & Rapid gate & $7.7+3.7$ & $8.5+6.1$ & 0.331 \\
\hline
\end{tabular}

*significant $p<0.05$ using independent t-test

BMl: body mass index; MUAC: mid upper arm circumference; WC: waist circumference; HC: hip circumference; CC: calf circumference; MOCA: Montreal cognitive assessment; ADL: activity of daily living; IADL: instrumental activity of daily living; GDS: Geriatric depression scale; 2min.st: 2 minutes step test; TUG: time up and go; BST: back scratch test; CSR: chair set and reach test; CST: chair stand test; RP: rapid pace

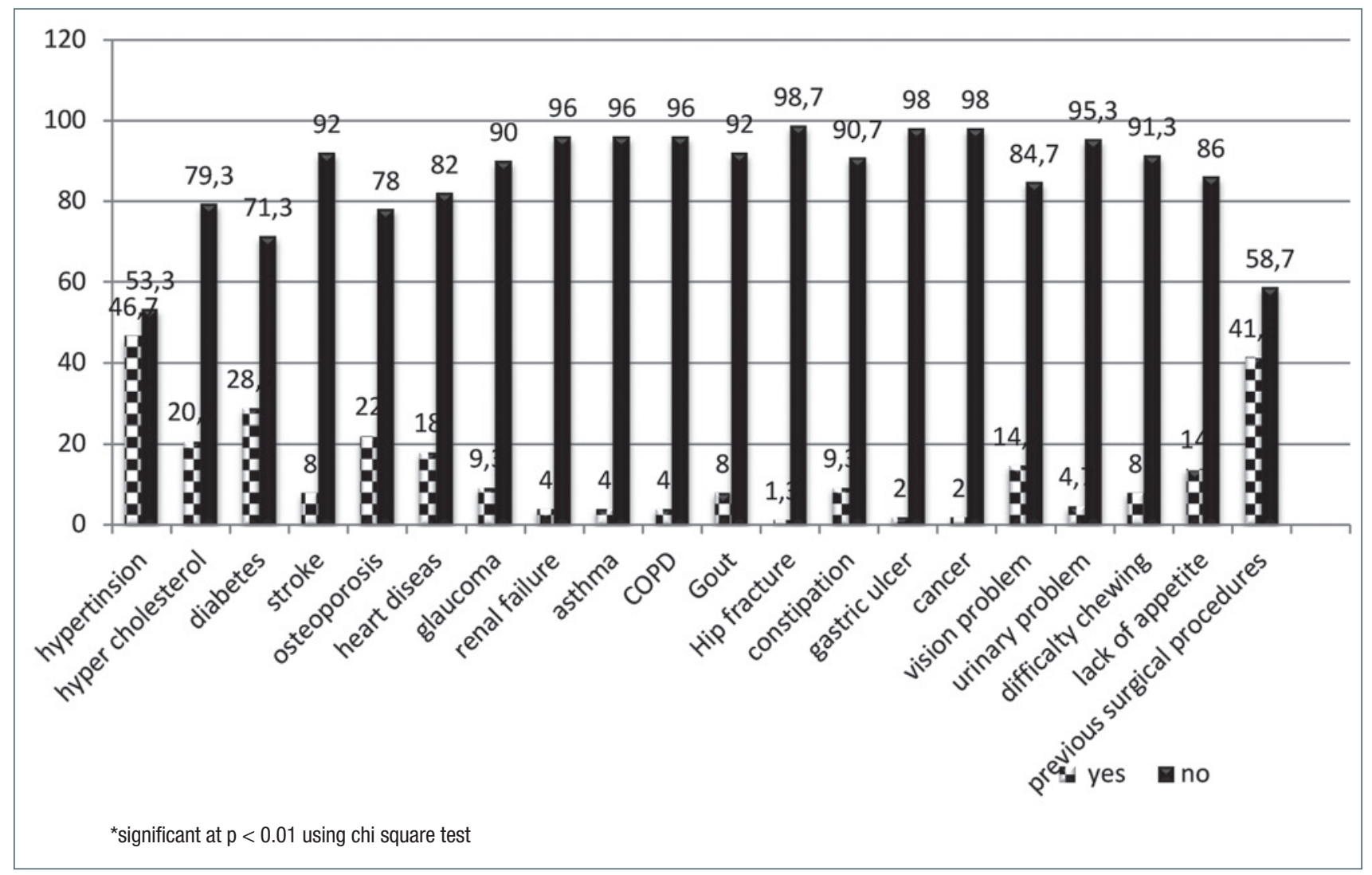

Figure 1. Medical history of the participants. 
Table III. Anthropometric measurements according to fall history and gender (mean \pm SD).

\begin{tabular}{|l|c|c|c|c|c|c|}
\hline & \multicolumn{3}{|c|}{ Males } & \multicolumn{3}{c|}{ Females } \\
\hline & Fallers & Non fallers & P-value & Fallers & Non fallers & P-value \\
\hline BMI & $31.8 \pm 2.43$ & $27.4 \pm 4.39$ & 0.21 & $32.3 \pm 0.07$ & $30.2 \pm 7.6$ & 0.30 \\
\hline MUAC & $32 \pm 2.82$ & $34.16 \pm 3.2$ & 0.47 & $34.4 \pm 5.56$ & $35.6 \pm 3.64$ & 0.60 \\
\hline WC & $131.5 \pm 117.5$ & $117.8 \pm 149$ & 0.46 & $120.6 \pm 11.3$ & $109.6 \pm 16.34$ & $0.004^{\star *}$ \\
\hline HC & $119.5 \pm 0.70$ & $114.9 \pm 16.5$ & $0.03^{*}$ & $124.2 \pm 9$ & $110.2 \pm 20.5$ & $0.000^{\star *}$ \\
\hline CC & $33.5 \pm 3.53$ & $34 \pm 5.42$ & 0.65 & $33.7 \pm 4.74$ & $35.06 \pm 7.07$ & 0.09 \\
\hline W : H ratio & $1.10 \pm 0.9$ & $0.98 \pm 1.04$ & 0.34 & $0.99 \pm 0.08$ & $0.98 \pm 0.11$ & 0.63 \\
\hline
\end{tabular}

${ }^{*} \mathrm{p}<0.05$ using Mann-Whitney test; ${ }^{* *} \mathrm{p}<0.01$ using Mann-Whitney test

BMI: body mass index; MUAC: mid upper arm circumference; WC: waist circumference; HC: hip circumference; CC: calf circumference

Table IV. Physical and cognitive function characteristics according to fall history and gender.

\begin{tabular}{|l|c|c|c|c|c|c|c|c|c|}
\hline & \multicolumn{3}{|c|}{ Total } & \multicolumn{3}{c|}{ Men } & \multicolumn{3}{c|}{ Women } \\
\hline & Fallers & Non fallers & P-value & Fallers & Non fallers & P-value & Fallers & Non fallers & P-value \\
\hline MOCA & $15.5 \pm 4.51$ & $18.4 \pm 4.99$ & $0.02^{\star}$ & $12.5 \pm 3.5$ & $19.5 \pm 5.31$ & 0.06 & $15.9 \pm 4.6$ & $17.2 \pm 4.32$ & 0.33 \\
\hline ADL & $0.35 \pm 0.9$ & $2.23 \pm 2.66$ & $0.000^{\star \star}$ & $1 \pm 1.41$ & $2.19 \pm 2.7$ & 0.43 & $0.26 \pm 0.79$ & $2.3 \pm 2.64$ & $0.00^{\star *}$ \\
\hline IADL & $5.05 \pm 2.53$ & $5.52 \pm 1.62$ & 0.47 & $1.5 \pm 2.12$ & $5.54 \pm 1.16$ & $0.00^{\star \star}$ & $5.53 \pm 2.23$ & $5.5 \pm 2.02$ & 0.95 \\
\hline GDS & $4.5 \pm 2.4$ & $4.80 \pm 3.08$ & 0.60 & $3 \pm 4.24$ & $4.69 \pm 3.29$ & 0.7 & $4.7 \pm 2.2$ & $4.93 \pm 2.83$ & 0.69 \\
\hline 2 min.st & $56.2 \pm 58.8$ & $119.1 \pm 41.3$ & $0.000^{\star \star}$ & $129.1 \pm 35.7$ & $129.1 \pm 35.7$ & $0.00^{\star \star}$ & $59.1 \pm 56.6$ & $107.9 \pm 44.5$ & $0.006^{\star \star}$ \\
\hline TUG & $27.6 \pm 21.4$ & $16.4 \pm 12.6$ & $0.05^{\star}$ & $27.5 \pm 17.6$ & $14.9 \pm 5.16$ & 0.5 & $27.6 \pm 22.4$ & $18.15 \pm 17.6$ & 0.14 \\
\hline BST & $35.8 \pm 17.0$ & $29.3 \pm 17.7$ & 0.15 & $43.5 \pm 19.1$ & $26.4 \pm 16.9$ & 0.42 & $34.8 \pm 17.2$ & $32.7 \pm 18.2$ & 0.67 \\
\hline CSR & $4.41 \pm 7.4$ & $3.43 \pm 3.6$ & 0.60 & $4 \pm 5.7$ & $3.3 \pm 3.9$ & 0.89 & $4.5 \pm 7.8$ & $3.6 \pm 3.9$ & 0.68 \\
\hline CST & $18.05 \pm 23.15$ & $18.7 \pm 11.8$ & 0.91 & $8 \pm 2.8$ & $17.8 \pm 11.7$ & $0.05^{\star}$ & $19.4 \pm 24.4$ & $19.7 \pm 11.96$ & 0.97 \\
\hline RP & $11.5 \pm 10.3$ & $7.8 \pm 3.80$ & $0.004^{\star \star}$ & $8.5 \pm 0.70$ & $7.8 \pm 3.8$ & 0.35 & $11.9 \pm 10.59$ & $7.8 \pm 3.9$ & $0.01^{*}$ \\
\hline
\end{tabular}

(mean $\pm \mathrm{SD}$ ) ${ }^{*} \mathrm{p}<0.05$ using Mann-Whitney test; ${ }^{* *} \mathrm{p}<0.01$ using Mann-Whitney test

MOCA: Montreal cognitive assessment; ADL: activity of daily living; IADL: instrumental activity of daily living; GDS: Geriatric depression scale; 2 min.st: 2 minutes step test; TUG: time up and go; BST: back scratch test; CSR: chair set and reach test; CST: chair stand test; RP: rapid gate

waist circumference were higher in fallers than nonfallers, whereas in men hip circumference was higher in fallers relative to non-fallers. The association between obesity and fall could be related to lower functional capacity as related to impaired balance and postural sway ${ }^{34}$. Also obesity is associated with high prevalence of depression and lower quality of life ${ }^{35}$. Programs that lead to weight loss were shown to improve postural balance may lead to decrease in risk of falls. One study reported almost two fold increase in the risk of fall among obese individuals. In this study higher risk of fall in obese people was associated with lower balance, lower quality of life, social function, body pain, and sedentary life and central distribution of fat ${ }^{36}$. In addition, it is more likely that obese people will suffer from higher rates of chronic diseases and hence will be taking many medications which could lead to increase in fall risk. People with cognitive impairment have high rate of fall $(60-80 \%)$ which is twice the rate of fall in regular older ${ }^{37}$. Fall among cognitively impaired people lead to dependence on others, need for care facilities and higher rate of mortality. In addition the cost associated with fall among this group is very high ${ }^{38}$. Mild cognitive impairment is transitional to between aging and dementia. $\mathrm{MCl}$ increases to $29 \%$ among older more than $85 y^{38}$. Unfortunately intervention studies indicate that older with cognitive problems are less responsive to intervention that aim to prevent falls that may include addressing polypharmacy issues, improve balance and strength and hearing and visual correction ${ }^{39}$. We used Montreal cognitive impairment (MOCA) test which is used to detect mild cognitive impairment, the suggested normal value for MOCA is 26-30 as taken from 90 healthy adult with mean age 72.8 y with higher education than our study group ${ }^{40}$. The value of MOCA in this study is lower than normal value, and fall risk seems to have lower MOCA. However normative value for MOCA does not exist for Palestinian population.

In this study there was high prevalence of cardiovascular disease among study participants. Even subclinical level of cardiac damage was associated with twofold increase in fall risk American participants ${ }^{41}$. In another group of patients with cardiovascular disease, increase in fall risk was linked to higher mortality and readmission 
to hospital risk ${ }^{42}$. Balanced training among a group of patients with cardiovascular disease improved TUG $(p<0.01)$; TUG and ADL in the faller participants were lower in non-fallers relative to faller in all study sample. We did not find other functional tests to be linked to fall risk among this group may be related to the fact that most of participants were less than $70 \mathrm{y}$ and many of them still working.

Depression was not related to risk of fall in this study group. Mostly this study participants lived with their families. In a study done among a group of Americans over 51, that depression was linked to falls with increasing frailty and admission to nursing home ${ }^{43}$.

\section{CONCLUSIONS}

This study was the first study among Palestinians older living in Hebron on the risk of falls. We included a $r$ sample of older living in rural part of the region which is not studied often, and was assessed many aspects related to risk of fall using validated questionnaires. In this study, we reported very low risk of fall among Palestinian older with high prevalence of cardiovascular diseases. Fall history was more common among females and was related to low cognitive impairment, obesity and reduced functional capacity as assessed by two minute step test, TUG and ADL. On the other hand, depression was not associated with fall risk in this study. However, this study is not without limitation including its cross sectional design which is not able to determine the cause and effect relationship between the risk of fall and other variables. The study sample included only two rural areas and didn't include the other living areas; cities and camps which are the common living areas in Palestine.

\section{Ethics approval and consent of participants}

The study was approved by Palestine Polytechnic University ethical committee in Hebron.

\section{Acknowledgment}

We would like to acknowledge the students who helped the researchers in the data collection. We would like to express our gratitude to the Palestinian older adults who agreed to participate in this study. Thanks are also to all co-researchers and fieldworkers involved in this study.

\section{Funding}

None.

\section{Conflict of interest}

The authors disclosed no conflict of interest.

\section{Author contributions}

All the authors contributed in the development of this manuscript.

\section{References}

1 Kinsella K, He W. An aging world: 2008. Washington, DC: US Government Printing Office; 2009. US Census Bureau. International Population Reports, PS95/09. 2009;1.

2 He W, Goodking D, Kowal P. An aging world: 2015. Unites States Census Bureau 2016, pp. 165.

3 Statistics PBo. Summary of demographic indicators in the Palestine by Region (http://www.pcbs.gov.ps/Portals/_ Rainbow/Documents/DEMO-2016-EEE.htm, Accessed 20/09/2019, 2016).

4 RA Seir, A Kharroubi. Implementation of palliative care in Palestine: cultural and religious perspectives. AQU Researchers Publications. 2017.

5 Khanuja K, Joki J, Bachmann G, et al. Gait and balance in the aging population: fall prevention using innovation and technology. Maturitas 2018;110:51-56. https://doi. org/10.1016/j.maturitas.2018.01.021

6 Das CP, Joseph S. Falls in elderly. J Indian Med Assoc 2005;103:136-140.

7 Tinetti ME, Williams CS. The effect of falls and fall injuries on functioning in community-dwelling older persons. J Gerontol A Biol Sci Med Sci 1998;53:M112-M119. https:// doi.org/10.1093/gerona/53A.2.M112

8 Ek S, Rizzuto D, Fratiglioni L, et al. Risk factors for injurious falls in older adults: the role of sex and length of follow-up. J Am Geriatr Soc 2019;67:246-253. https://doi. org/10.1111/jgs. 15657

9 Tinetti ME, Kumar C. The patient who falls: "It's always a trade-off". JAMA 2010;303:258-266. https://doi. org/10.1001/jama.2009.2024

10 Tinetti ME, Speechley M, Ginter SF, et al. Risk factors for falls among elderly persons living in the community. $N$ Engl J Med 1988;319:1701-1708. https://doi.org/10.1056/ NEJM198812293192604

11 T. Kvelde, SR Lord, Close JCT, et al. Depressive symptoms increase fall risk in older people, independent of antidepressant use, and reduced executive and physical functioning. Arch Gerontol Geriatr 2015;60:190-195. https:// doi.org/10.1016/j.archger.2014.09.003

12 Welmer AK, Rizzuto D, Laukka EJ, et al. Cognitive and physical function in relation to the risk of injurious falls in older adults: a population-based study. J Gerontol A Biol Sci Med Sci 2017;72:669-675.

13 Follis S, Cook A, Bea JW, et al. Association between sarcopenic obesity and falls in a multiethnic cohort of postmenopausal women. J AM Geriatr Soc 2018;66:23142320. https://doi.org/10.1111/jgs.15613 
14 SSY Yeung, EM Reijnierse, VK Pham, et al. Sarcopenia and its association with falls and fractures in older adults: a systematic review and meta-analysis. J Cachexia Sarcopenia Muscle 2019;10:485-500. https://doi.org/10.1002/ jcsm. 12411

15 Neri SGR, Gadelha AB, de David AC, et al. The association between body adiposity measures, postural balance, fear of falling, and fall risk in older community-dwelling women. J Geriatr Phys Ther 2019;42:E94-E100. https:// doi.org/10.1519/JPT.0000000000000165

16 Mangani I, Cesari M, Russo A, et al. Physical function, physical activity and recent falls. Results from the "Invecchiamento e Longevità nel Sirente (iISIRENTE)" Study. Aging Clin Exp Res 2008;20:234-241. https://doi. org/10.1007/BF03324778

17 Fischer B, Hoyt W, Maucieri L, et al. Performance based assessment of falls risk in older veterans with executive dysfunction. J Rehabil Res Dev 2014;51:263. https://doi. org/10.1682/JRRD.2013.03.0075

18 Bohannon RW. Grip strength: an indispensable biomarker for older adults. Clinical Interv Aging 2019;14:1681. https://doi.org/10.2147/CIA.S194543

19 Wiśniowska-Szurlej A, Wilmowska-Pietruszyńska A. An assessment of factors related to disability in ADL and IADL in elderly inhabitants of rural areas of south-eastern Poland. Ann Agricult Environ Med 2018;25:504-511. https:// doi.org/10.26444/aaem/81311

20 Ritchie K. Mild cognitive impairment: an epidemiological perspective. Dialogues Clin Neurosci 2004;6:401-408. https://doi.org/10.31887/DCNS.2004.6.4/kritchie

21 Allali G, Launay CP, Blumen HM, et al. Falls, cognitive impairment, and gait performance: results from the GOOD initiative. J Am Med Dir Assoc 2017;18:335-340. https:// doi.org/10.1016/j.jamda.2016.10.008

22 Orces $\mathrm{CH}$. Prevalence and determinants of falls among older adults in Ecuador: an analysis of the SABE I Survey. Curr Gerontol Geriatr Res 2013;2013. https://doi. org/10.1155/2013/495468

23 Bohannon RW. Hand-grip dynamometry predicts future outcomes in aging adults. J Geriatr Phys Ther 2008;31:3-10. https://doi.org/10.1519/00139143-200831010-00002

24 Jones CJ, Rikli RE, Beam WC. A 30-s chair-stand test as a measure of lower body strength in community-residing older adults. Res Quart Exerc Sport 1999;70:113-119. https://doi.org/10.1080/02701367.1999.10608028

25 Merellano-Navarro E, Collado-Mateo D, García-Rubio J, et al. Validity of the International Fitness Scale "IFIS" in older adults. Experim Gerontol 2017;95:77-81. https://doi. org/10.1016/j.exger.2017.05.001

26 Downton JH, Andrews K. Prevalence, characteristics and factors associated with falls among the elderly living at home. AGING CLIN EXP RES 1991;3:219-228. https:// doi.org/10.1007/BF03324009

27 Kamel MH, Abdulmajeed AA, Ismail SE-S. Risk factors of falls among elderly living in Urban Suez-Egypt. Pan Afr Med 2013;14. https://doi.org/10.11604/ pamj.2013.14.26.1609
28 Enriquez de Luna-Rodriguez M, Aranda-Gallardo M, Canca-Sanchez JC, et al. Profile of the patient who suffers falls in the hospital environment: multicenter study. Enferm Clin 2020;30:236-243.

29 Malini FM, Lourenço RA, Lopes CS. Prevalence of fear of falling in older adults, and its associations with clinical, functional and psychosocial factors: the frailty in Brazilian older people Rio de Janeiro Study. Geriatr Gerontol Int 2016;16:336-344. https://doi.org/10.1111/ggi.12477

30 Murphy SL, Dubin JA, Gill TM. The development of fear of falling among community-living older women: predisposing factors and subsequent fall events. J Gerontol A Biol Sci 2003;58:M943-M947. https://doi.org/10.1093/ gerona/58.10.M943

31 Greenberg MR, Moore EC, Nguyen MC, et al. Perceived fall risk and functional decline: gender differences in patient's willingness to discuss fall risk, fall history, or to have a home safety evaluation. YJBM 2016;89:261-267.

32 Fukukawa Y, Kozakai R, Niino N, et al. Social support as a moderator in a fall prevention program for older adults. J Gerontological Nurs 2008;34:19-25. https://doi. org/10.3928/00989134-20080501-05

33 Trevisan C, Rizzuto D, Maggi S, et al. Impact of social network on the risk and consequences of injurious falls in older adults. J Am Geriatr Soc 2019;67:1851-1858. https://doi.org/10.1111/jgs.16018

34 JM Friedmann, T Elasy, GL Jensen. The relationship between body mass index and self-reported functional limitation among older adults: a gender difference. J Am Geriatr Soc 2001;49:398-403. https://doi. org/10.1046/j.1532-5415.2001.49082.x

35 Katz DA, McHorney CA, Atkinson RL. Impact of obesity on health-related quality of life in patients with chronic illness. J Gen Intern Med 2000;15:789-796. https://doi. org/10.1046/j.1525-1497.2000.90906.x

36 Fjeldstad C, Fjeldstad A, Acree S, et al. The influence of obesity on falls and quality of life. Dyn Med 2008;7:4. https://doi.org/10.1186/1476-5918-7-4

37 Tinetti ME, Speechley M, Ginter SF. Risk factors for falls among elderly persons living in the community. $N$ Eng J Med 1988;319:1701-1707. https://doi.org/10.1056/ NEJM198812293192604

38 Montero-Odasso M, Verghese J, Beauchet O, et a. Gait and cognition: a complementary approach to understanding brain function and the risk of falling. J Am Geriatr Soc 2012;60:2127-2136. https://doi. org/10.1111/j.1532-5415.2012.04209.x

39 Oliver D, Connelly JB, Victor CR, et al. Strategies to prevent falls and fractures in hospitals and care homes and effect of cognitive impairment: systematic review and meta-analyses. BMJ 2007;334:82. https://doi.org/10.1136/ bmj.39049.706493.55

40 Rossetti H, Lacritz L, CullumM, et al. Normative data for the Montreal Cognitive Assessment (MoCA) in a populationbased sample. Neurology 2011;77:1272-1275. https:// doi.org/10.1212/WNL.0b013e318230208a 
41 SP Juraschek, Daya N, Appel LJ, et al. Subclinical cardiovascular disease and fall risk in older adults: results from the atherosclerosis risk in communities study. J Am Geriatr Soc 2019;67:1795-1802. https://doi.org/10.1111/ jgs. 16041

42 Manemann SM, Chamberlain AM, Boyd CM, et al. Fall risk and outcomes among patients hospitalized with cardiovascular disease in the community. Circ Cardiovasc Qual Outcomes 2018;11:e004199. https://doi.org/10.1161/ CIRCOUTCOMES.117.004199
43 Lohman MC, Mezuk B, Dumenci L. Depression and frailty: concurrent risks for adverse health outcomes. Aging Ment Health 2017;21:399-408. https://doi.org/10.1080/136078 63.2015.1102199 